\title{
Research of Spined Heat-Exchanging Pipes
}

\author{
Kirill Akulov ${ }^{1, *}$, Vasiliy Golik ${ }^{1}$, Mikhail Chekardovsky ${ }^{1}$, and Anatoly Serebrennikov ${ }^{1}$ \\ ${ }^{1}$ Industrial University of Tyumen, 625001 Volodarskogo str. 38, Tyumen, Russia
}

\begin{abstract}
Work is devoted to a research of spined heat-exchanging pipes that are assumed to use in air-cooler exchangers (ACE). The proposed new geometry of finning allows intensifying heat exchange and improving the efficiency of air coolers. It is caused by the increased area of finned surface with a value of finning ratio (the ratio of the area of the smooth pipe to a finned one) to 42.7 , while in the commercially available ACE, the figure is 22. Besides, the geometrical arrangement of the pin fins turbulizes the airflow. It should be mentioned that an easier method of manufacturing of heat exchanging pipes is proposed to use, which will reduce their costs. The proposed heat exchange pipes are made by winding cut aluminum strip to the supporting pipe or stretching stamped blanks on it. To increase the efficiency of the heat exchange surface pin fins should be as thin and long as possible; however, their strength should be sufficient for deformation-free operation. Fins should be staggered to maximize the distance between them. Spined heat-exchange pipes are designed to operate in a commercially produced ACE and their service is carried out similarly to commercially produced transversely finned pipes.
\end{abstract}

\section{Introduction}

Gas industry at the present stage of development, is characterized by the fact that its resource base is located in remote northern regions of the country, and key gas consumers in the central, industrial areas and abroad. This causes the necessity to transport natural gas at very long distances [1-23]. Under such circumstances, the final price for natural gas includes a significant percentage of transportation costs $[4,7,8,16]$. It should be noted that at compressor stations with gas turbine-driven superchargers (which have the vast majority) most of the electricity spent on gas transportation is consumed on its cooling. Therefore, improvement of the cooling system is one of the primary challenges facing the gas industry to reduce energy consumption for gas transport and its cost.

\section{The object of research}

In this study we focus on one of the directions of intensification of the cooling of natural gas associated with convection on the surface of heat-exchanging pipes of air coolers (ACE) (Figure 1.).

*Corresponding author: akukir@gmail.com 


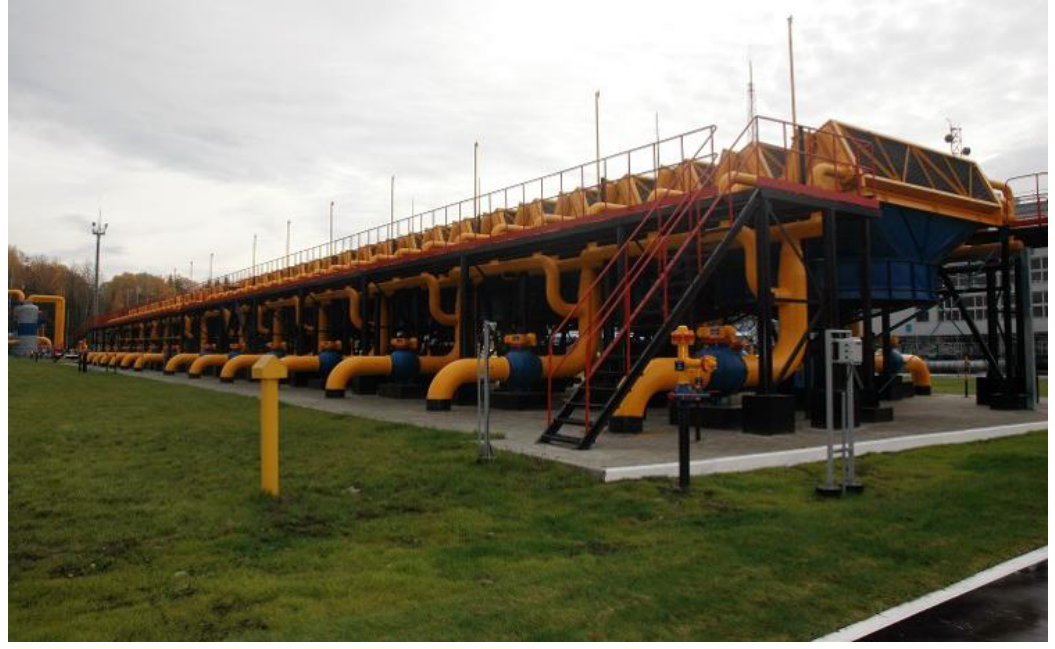

Fig. 1. Air coolers on compressor station.

In ACE, commercially available transversely finned heat-exchange pipes are used (Figure 2.). The main way to increase the efficiency of a heat exchange surface is the increase of finning area $[2,10,14,15,18,19]$. This metal-intensive method is characterized by the fact that with an increase in finning ratio, increases the relative depth of intercostal gap, root zone gradually excluded from the heat and the heat emission growth slows down. This problem was solved using a pin fining [1, 12, 13, 17] (Figure 3a., Figure 6.). This type of finning is almost not been studied and it was researched only with small finning coefficients not applicable in industrial air coolers. An advantage of heat exchanging pipes is that fins in the transverse plane are disposed at an angle to each other and by increasing of the length of the fin an intercostal spacing increase. Therefore, such a fin may have considerable height of fins without the formation of dead zones. The location and shape of fins contributes to the turbulence flow while turbulization in the intercostal cavities of transversely finned pipes is weak. It is noteworthy that the finned convective surface is not inclined to clogging and has an improved clean ability [20].

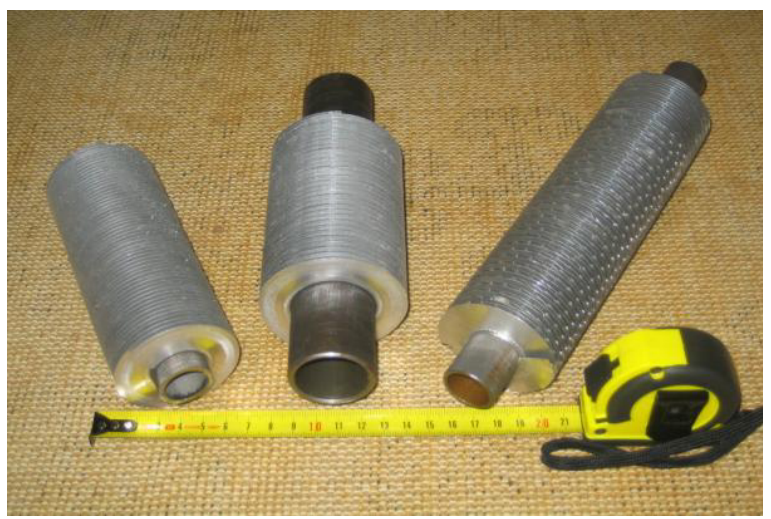

Fig. 2. Heat exchange pipes with wound spiral finning.

A technological way to the supporting pipe finning with pin fins was developed. For this purpose, the supporting tube of winding tape should make transverse cuts or incisions at intervals of several millimeters, depending on the thickness of the pins. Received petals will form pins of the radiator when pulling on the blank (Figure 3b.). The process is similar to the production of standard spiral-wound fins. However, there becomes no need in rolling 


\section{TPACEE-2016}

rollers, flattening the ribbon to give it bending (Figure 3a.). Thus, the ribbon winding process can be produced without special equipment on a conventional lathe. Simplification of the production process will inevitably lead to products cheapening.

\section{Methods}

Experimental setup study of pipes designed and manufactured for the study of thermal characteristics of single finned tubes in air flow speed range up to $6 \mathrm{~m} / \mathrm{s}$. Installation diagram of the experimental research of finned tubes is shown in Figure 4. It represents a low-pressure open-loop wind tunnel with a width of the flow-cross section of $0.23 \mathrm{~m}$ and a height of $0.34 \mathrm{~m}$. The air temperature is defined by two benchmark platinum resistance thermometers Pt100 class 1, one of which is a dry thermometer and another is wet. To adjust the air flow a section of centrifugal fans with variable speed is used. For alignment and smoothing the flow of air pressure pulsations after the fan section, the narrowing element was installed. Volumetric flow rate was measured by the Venturi nozzles, built into the flowmeter.

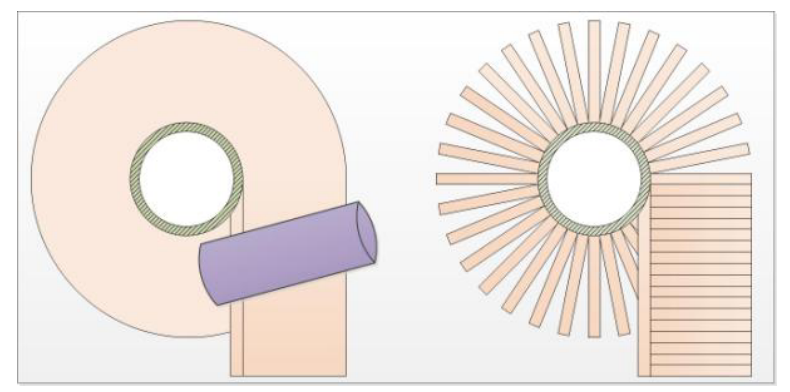

Fig. 3. Formation schemes: a) scheme of bending formation of the spiral fin by rolling rollers. b) scheme of formation of pin fins from ribbon with notches.

\$yudied finned tubes had pin finning of a bound profile with geometrical parameters shown in Table 1. Finned tubes impaled on tubular electrical heaters (TEHs) with interference at nominal fit diameter of $10 \mathrm{~mm}$. The length of finned tubes and the length of the active part of electrical heating element $=230 \mathrm{~mm}$. The voltage at the electric heating elements $\mathrm{U}=220 \mathrm{~V}$, and their active resistance $\mathrm{RU}=120-130 \mathrm{ohm}$. The ends of the ribbed pipes are heat-insulated with fluoroplastic caps.

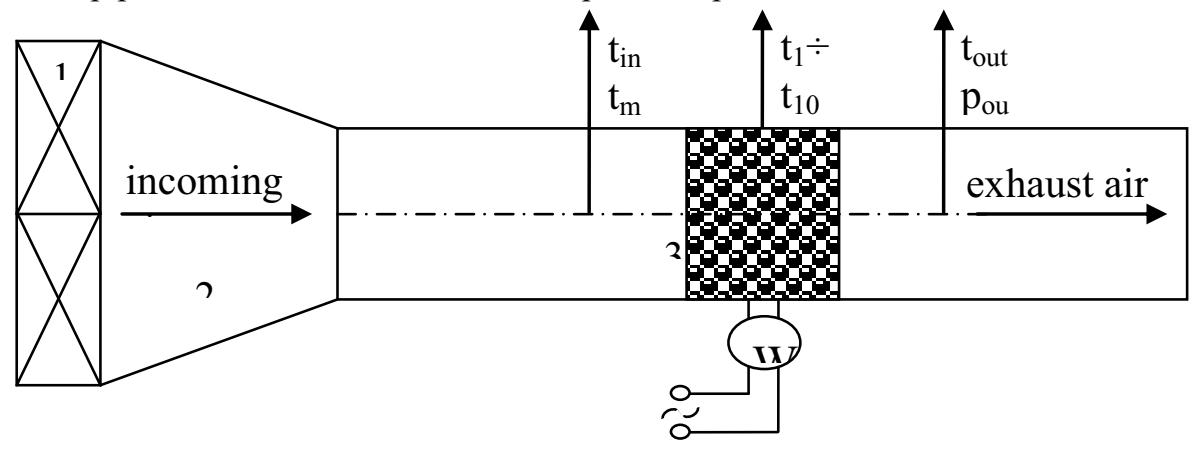

Fig. 4. Schematic scheme of the installation of experimental studies of finned tubes. 1. Section of fans with variable frequency of rotation; 2 . narrowing element; 3 . The studied finned pipe.

Experimental studies of heat emission of finned tubes consisted of 6 sets (the number of finned tubes). In each set, one finned pipe was studied. The finned pipes were heated by 


\section{TPACEE-2016}

means of electric heaters built into them. To reduce the TCR between the finned pipes and heating elements, the inner surface of the pipe is pushed over the outer surface of the electrical heating element with an interference fit.

The heat transfer coefficient on the surface of the finned tube was determined by averaging over the entire outer surface of the finning, which is the sum of surfaces pits, tops and sides of fins. To calculate the heat transfer coefficient, the value of the forced convective component of the heat flow as the difference between the electric power heating finned tube of electric heaters and radiant heat flow component, as well as natural convective component of the heat flow was used [21]. Here radiant heat flow component was determined by the surface temperature of the finned tube and the walls of the channel of the wind tunnel. The ends of the finned tubes were heat-insulated, so heat loss from the ends was neglected.

Table 1. The geometrical finning parameters of the samples of finned pipes.

\begin{tabular}{|c|c|c|c|c|c|c|}
\hline $\begin{array}{c}\text { No of } \\
\text { sample }\end{array}$ & $\begin{array}{c}\text { finning } \\
\text { coefficient } \\
\psi\end{array}$ & $\begin{array}{c}\text { intercostal } \\
\text { distance } \\
\delta[\mathrm{mm}]\end{array}$ & $\begin{array}{c}\text { fin } \\
\text { thickness } \\
\delta \mathrm{f}[\mathrm{mm}]\end{array}$ & $\begin{array}{c}\text { The fin } \\
\text { height } \\
\mathrm{hf}[\mathrm{mm}]\end{array}$ & $\begin{array}{c}\text { The } \\
\text { diameter of } \\
\text { the support } \\
\text { tube d } \\
{[\mathrm{mm}]}\end{array}$ & $\begin{array}{c}\text { The outer } \\
\text { diameter of } \\
\text { the finning D } \\
{[\mathrm{mm}]}\end{array}$ \\
\hline 1 & 41.7 & 2 & 3 & 95 & 35 & 22.5 \\
\hline 2 & 37.4 & 2 & 3 & 85 & 35 & 20.5 \\
\hline 3 & 33.1 & 2 & 3 & 75 & 35 & 18.5 \\
\hline 4 & 28.9 & 2 & 3 & 65 & 35 & 16.5 \\
\hline 5 & 24.6 & 2 & 3 & 55 & 35 & 14.5 \\
\hline 6 & 20.3 & 2 & 3 & 45 & 35 & 12.5 \\
\hline
\end{tabular}

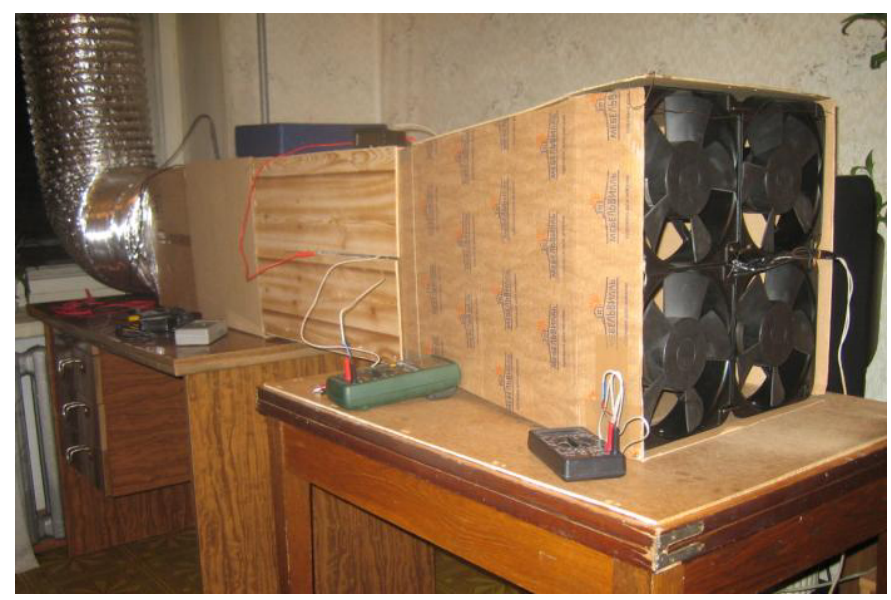

Fig. 5. The appearance of machine of the experimental studies of finned tubes.

The temperature of finned surface elements was measured by copper-nickel (C-N) thermocouples. The temperature of peaks was measured by fins glued on a hot melt adhesive Alsil-2 to the ends of fins thermocouples. The temperatures of fins foundation was measured by fins, glued on a hot melt adhesive Alsil- 2 to the base thermocouples. The rate of air flow sequentially took values from 0.5 to $6 \mathrm{~m} / \mathrm{s}$. The time of exit of a machine on a nominal mode at steady-state value of air flow rate and temperature of the surface of the finned tube is about 1 hour. After the installation of the nominal mode at steady-state value of air flow rate, such parameters as air speed, current and voltage of the heater, the average temperature of the sample, the temperature of the incoming and outgoing flow were measured. For each value of air flow rate, all values were measured by alarm-control 


\section{TPACEE-2016}

system for 70 minutes at intervals of 30 seconds. For the user, the averaged values were displayed and used for further processing.

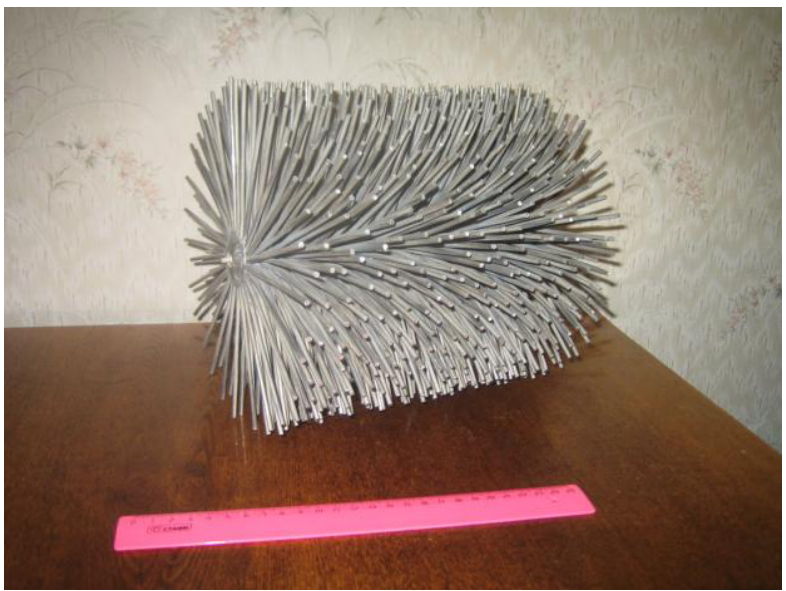

Fig. 6. Appearance of the sample №1.

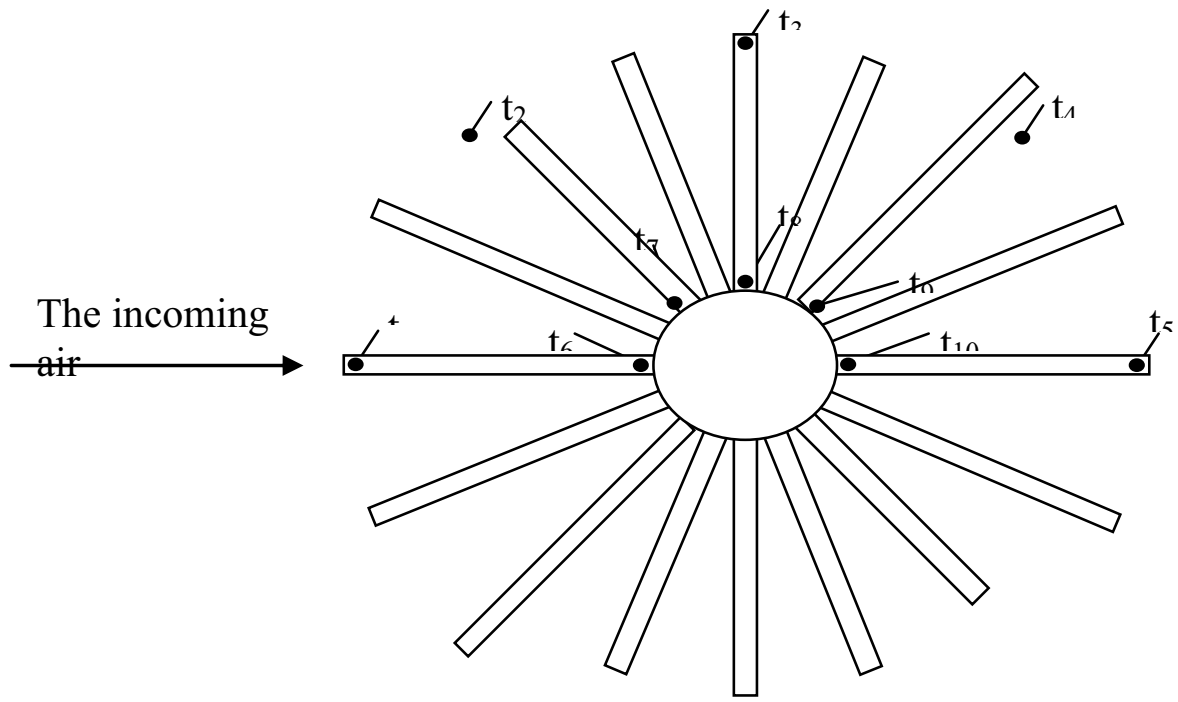

Fig. 7. The layout of thermocouples on the test sample.

To simplify the calculations, program was designed, the algorithm of which is presented in Figure 8. The program was written in tabular processor Microsoft Excel of Microsoft Office. The resulting calculation values of Nusselt and Reynolds numbers were approximated by the equation $[5,11,20]$ :

$$
N u=c \cdot \operatorname{Re}^{m}
$$

where $\mathrm{Nu}$ - Nusselt number from the air; Re - Reynolds number from the air; $\mathrm{c}$ and $\mathrm{m}$ constant coefficients. 


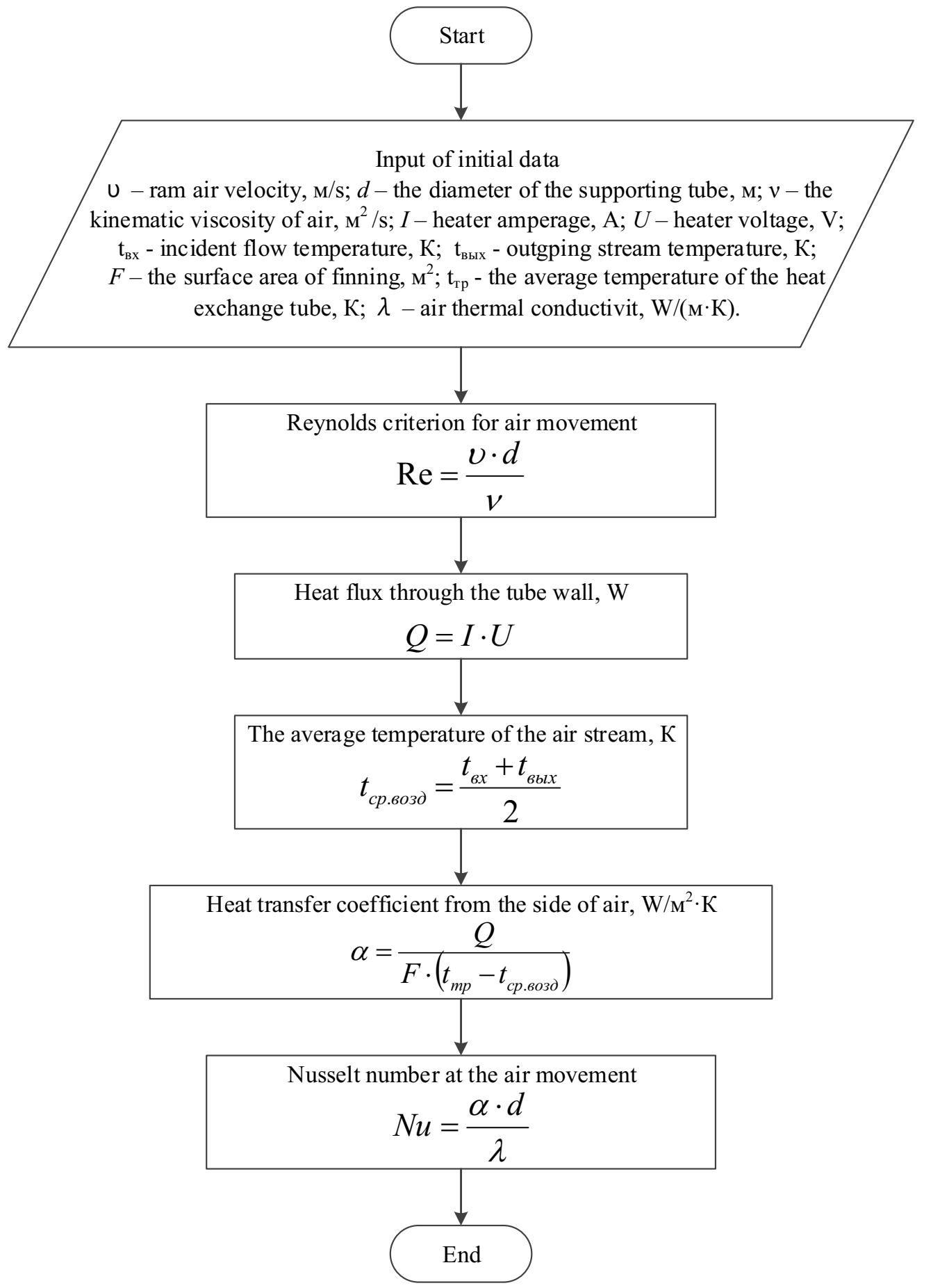

Fig. 8. Algorithm of processing of experimental data.

The generalized equation for the sample №1 is: 


$$
\mathrm{Nu}=0,1454 \cdot \mathrm{Re}^{0,541}
$$

The generalized equation for the sample №2 is:

$$
\mathrm{Nu}=0,1528 \cdot \mathrm{Re}^{0,541}
$$

The generalized equation for the sample №3 is:

$$
\mathrm{Nu}=0,1602 \cdot \mathrm{Re}^{0,541}
$$

The generalized equation for the sample №4 is:

$$
\mathrm{Nu}=0,1676 \cdot \mathrm{Re}^{0,541}
$$

The generalized equation for the sample №5 is:

$$
\mathrm{Nu}=0,175 \cdot \operatorname{Re}^{0,541}
$$

The generalized equation for the sample №6 is:

$$
\mathrm{Nu}=0,1824 \cdot \mathrm{Re}^{0,541}
$$

\section{Results and Discussion}

The dependence of the Nusselt number for total heat exchange surface of the Reynolds number is shown in Figure 9. For comparison, the figure shows the characteristics used in the ACE heat exchanging pipes coefficients with finning 22, 14.6 and $9[3,6,9]$ (corresponding pipe 1, 2 and 3 in Figure 9.). For the reasons of clarity, characteristics of a smooth pipe are also shown.

Characteristics of spined pipes are more gentle than the transversely finned pipes. Heat transfer of spined pipes with finning factor 22 is more than transversely finned at $77 \%$ in the area $\operatorname{Re}=5000$ and $41 \%$ at $\operatorname{Re}=40000$. Spined pipe with a coefficient of finning 41.7 has heat transfer more by $190 \%$ and $131 \%$, respectively.

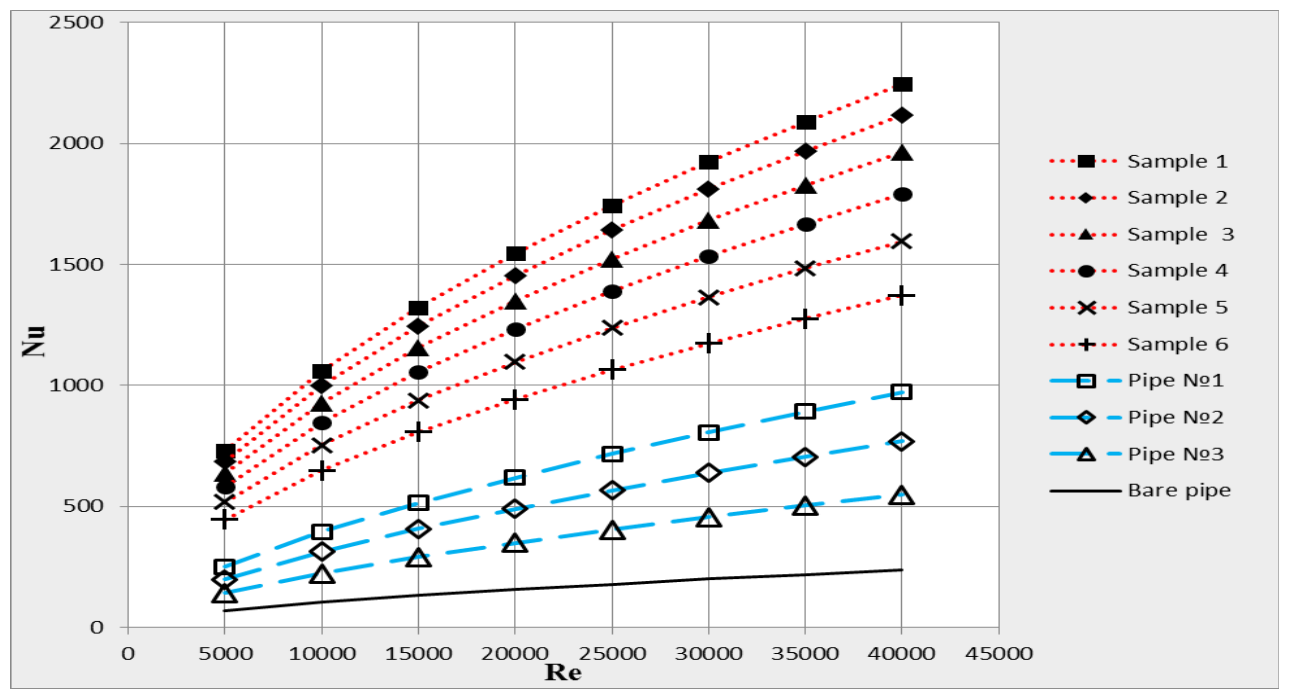

Fig. 9. Heat transfer of the researched and existing heat-exchange pipes. 


\section{Conclusion}

Compared to standard, heat exchanger pipes studied in research possess enhanced heat transfer. Their manufacturing is simpler and allows doing without special equipment; the process can be established on a conventional lathe. Spined convective surface is not prone to clogging, and has an improved clean ability. These advantages make it possible to reduce the cost and increase the efficiency of heat exchange of air coolers.

\section{References}

1. K. Akulov, Problems of Functioning Transport Systems: Proceedings of the scientificpractical conference of students, graduate students and young scientists, TSOGU, Tyumen, 42-44 (2012)

2. K. Akulov, V. Golik, Problems of Functioning Transport Systems: Proceedings of the scientific-practical conference of students, graduate students and young scientists, TSOGU, Tyumen, 27-32 (2015)

3. K. Akulov, A. Istomina, New technologies - oil and gas regions: Proceedings of allrussian scientific-practical conference, TSOGU, Tyumen, 44-45 (2011)

4. K. Akulov, P. Matantsev, Oil and Gas Terminal: Proceedings of the International scientific and technical conference, TSOGU, Tyumen, 15-18 (2015)

5. K. Akulov, P. Matantsev, New technologies - oil and gas regions: Proceedings of allrussian scientific-practical conference, TSOGU, Tyumen, 45-49 (2011)

6. K. Akulov, P. Matantsev, A. Istomina, Oil and gas in Western Siberia: Proceedings of the international scientific conference, TSOGU, Tyumen, 5-8 (2011)

7. K. Akulov, V. Golik, T. Ponomareva, Fundamental researches, 12-3, 453-456 (2015)

8. G. Bakhmat, N. Eremin, O. Stepanov, Air cooling devices at gas compressor station (Nedra, SPb, 1994)

9. A. Bessonny, G. Dreytser, V. Kuntysh, ed. V. Kuntysh, Basement of calculation and designing of heat exchangers of air cooling: Dictionary (Nedra, SPb, 1996)

10. K. Degtyarev, A. Soloviev, Young scientist, 1(8), 107-112 (2011)

11. A. Gabdrahmanov, N. Garris, Oil and Gas Business, 1, 44 (2003)

12. Handbook of Heat Exchangers, V. 1 (Energoatomisdat, Moscow, 1987)

13. V. Kuntysh, A. Suhotskiy, S. Filatov, A. Zhdanovich, Chemical equipment, 11, 40-43 (2013)

14. V. Nekrasov, S. Dudin, Yu. Zemenkov, R. Levitin, Territory Neftegaz, 11, 79-82 (2014)

15. V. Nekrasov, R. Levitin, A. Mayer, Higher Educational Institutions News. Oil and Gas, 5, 63-65 (2014)

16. V. Nekrasov, R. Levitin, Yu. Zemenkov, Journal of the Tajik National University. Series of Natural Sciences, 1-2, 140-144 (2015)

17. V. Nekrasov, Yu. Zemenkov, Pipeline transport: Theory and Practice, 6, 24-26 (2012)

18. R. Levitin, Yu. Zemenkov,. Neftyanoe khozyaystvo - Oil Industry, 1, 110-114 (2016)

19. V. Antip'ev, A. Nevolin, Yu. Zemenkov, Neftyanoe Khozyaistvo - Oil Industry, 10, 46-48 (1981)

20. R. Mamadaliev, V. Kuskov, Yu. Zemenkov, A. Popova, Applied Mechanics and Materials, 770, 19-22 (2015)

21. V. Kurushina, Yu. Zemenkov, WIT Transactions on Ecology and the Environment, 190, 2, 881-888 (2014)

22. M. Omelyanyuk, Neftepromyslovoe delo, 6, 62-65 (2008)

23. M. Chekardovsky, V. Ivanov, A. Khamidov, S. Chekardovsky, K. Ilyukhin, Higher Educational Institutions News. Oil and Gas, 1, 44-49 (2008) 